\title{
Downregulation of miR-374b-5p promotes chemotherapeutic resistance in pancreatic cancer by upregulating multiple anti-apoptotic proteins
}

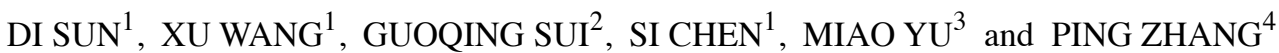 \\ ${ }^{1}$ Department of Colorectal and Anal Surgery, The First Hospital of Jilin University, Changchun, Jilin 130000; \\ ${ }^{2}$ Department of Ultrasound, The China-Japan Union Hospital of Jilin University, Changchun, Jilin 130000; \\ ${ }^{3}$ Center for Private Medical Service and Healthcare, The First Hospital of Sun Yat-sen University, \\ Guangzhou, Guangdong 510080; ${ }^{4}$ Department of Hepatobiliary and Pancreas Surgery, \\ The First Hospital of Jilin University, Changchun, Jilin 130000, P.R. China
}

Received October 31, 2017; Accepted February 6, 2018

DOI: $10.3892 /$ ijo.2018.4315

\begin{abstract}
Resistance to first-line chemotherapeutic drugs such as gemcitabine contributes to the poor prognosis of patients with pancreatic cancer. MicroRNAs (miRNA) regulate chemoresistance in pancreatic cancer. By analyzing the miRNA sequencing dataset of pancreatic cancer from The Cancer Genome Atlas, it was demonstrated that miR-374b-5p expression was dramatically reduced in pancreatic cancer tissues compared with adjacent normal tissues, as well as decreased in chemoresistant compared with chemosensitive pancreatic carcinoma tissues. The decreased expression of miR-374-5p was associated with poor overall and progressionfree survival in patients with pancreatic cancer. Furthermore, increased expression of miR-374b-5p abrogated, while the silencing miR-374b-5p increased the chemoresistance of pancreatic cancer cells to gemcitabine in vitro. Importantly, the upregulation of miR-374b-5p ameliorated the chemoresistance of pancreatic cancer cells to gemcitabine in vivo. It was also demonstrated that miR-374b-5p targeted several antiapoptotic proteins, including B-cell lymphoma 2, Baculoviral IAP Repeat Containing 3 and X-linked inhibitor of apoptosis in pancreatic cancer cells, which further attenuated chemoresistance in pancreatic cancer. Therefore, the results of the current study indicate that miR-374b-5p serves as a potential diagnostic marker. It also suggests that miR-374b-5p sensitizes cells to chemotherapy and may be used in combination with chemotherapeutic agents such as gemcitabine to treat patients with pancreatic cancer.
\end{abstract}

Correspondence to: Professor Ping Zhang, Department of Hepatobiliary and Pancreas Surgery, The First Hospital of Jilin University, 71 Xinmin Street, Changchun, Jilin 130000, P.R. China E-mail: azhangpinga@126.com

Key words: microRNA-374b-5p, chemotherapeutic resistance, anti-apoptotic proteins, diagnostic marker and pancreatic cancer

\section{Introduction}

Pancreatic cancer is one of the most devastating malignancies of the gastrointestinal tract as well as one of the most common causes of cancer-associated mortality worldwide (1). Surgery is the optimal method of treating patients with pancreatic cancer; however, the application of surgical therapy in patients with pancreatic cancer is limited, as the majority of patients are at an advanced stage of the disease at diagnosis. Indeed, $\leq 20 \%$ of patients with pancreatic cancer are suitable to undergo such surgery (2). For the majority of patients with pancreatic cancer, the primary method of treatment is chemotherapy and gemcitabine is the most common chemotherapeutic drug used to treat patients with inoperable pancreatic cancer. Although progress has been made in the treatment of pancreatic cancer over the past few decades, the median survival time of such patients remains $<1$ year $(3,4)$. The failure of chemotherapy is attributed to the complete resistance against chemotherapeutic drugs and chemotherapy resistance presents a major clinical challenge in the treatment of cancer. Therefore, it is important to understand the molecular mechanisms underlying the development of chemoresistance in pancreatic cancer in order to develop effective therapeutic targets.

The resistance of cancer cells to a wide spectrum of chemotherapeutic drugs may be associated with the intrinsic resistance of cancer cells and/or acquired resistance following several cycles of chemotherapy (5). The most common mechanism by which chemoresistance arises is the development of efflux pumps on the surface of tumor cells that eject anticancer drugs from inside tumor cells to the outside environment (6). Other anti-drug mechanisms include the upregulation of DNA repair enzymes, insensitivity to drug-induced apoptosis, stromal proliferation, induction of drug-detoxifying mechanism and reduced angiogenesis, all of which serve a crucial role in the development of drug resistance of cancer cells (7-11). Therefore, it is crucial to develop comprehensive understanding of the specific mechanism by which chemoresistance arises in pancreatic cancer cells in order to identify a novel therapeutic strategy to overcome chemoresistance 
and improve the clinical therapeutic response of patients with pancreatic cancer.

Micro (mi)RNAs post-transcriptionally regulate a variety of target genes by binding to the 3'-untranslated region (3'-UTR) of their target genes (12). The aberrant expression of miRNAs serves either oncogenic or tumor-suppressive roles in the tumorigenesis, progression and metastasis of various types of cancer (13-19). Previous studies have demonstrated that miRNAs are important mediators of chemoresistance in pancreatic cancer. Chaudhary et al (20) reported that miR-205-5p was differentially downregulated in pancreatic cancer cells and tissues. It was also demonstrated that the ectopic expression of miR-205-3p in combination with gemcitabine significantly reduced the proliferation and tumor growth of pancreatic cancer cells in mouse models (20). Furthermore the oncogenic miRNA miR-181c is dramatically elevated in pancreatic cancer tissues and this high expression of miR-181c induces chemoresistance in pancreatic cancer by inactivating the Hippo signaling pathway (21). These results indicate that the dysregulation of miRNAs serves an important role in the development of chemoresistance in pancreatic cancer.

The present study measured miR-374b-5p expression by reverse transcription-quantitative polymerase chain reaction (RT-qPCR) and evaluated whether there was an association between miR-374b-5p levels, clinicopathological characteristics and overall and progression-free survival of patients with pancreatic cancer. The effects of miR-374b-5p expression on chemoresistance were examined by performing gain or loss of function assays in vitro and in vivo and the potential targets of miR-374b-5p were identified using bioinformatics analysis, RT-qPCR, western blotting, luciferase reporter and RNA immunoprecipitation assays. The results revealed that the decreased expression of miR-374b-5p promoted the resistance of pancreatic cancer cells to the chemotherapeutic reagent gemcitabine by enhancing the expression of several anti-apoptotic proteins, including B-cell lymphoma 2 (BCL2), Baculoviral IAP Repeat Containing 3 (BIRC3) and X-linked inhibitor of apoptosis (XIAP). These results suggest that the delivery of miR-374b-5p may be developed as a novel therapeutic strategy to treat patients with chemotherapy resistant pancreatic cancer.

\section{Materials and methods}

Cell lines and cell culture. The human pancreatic cancer cell lines BxPC-3, PANC-1, AsPC-1, SW1990, Capan-1, Capan-2, CFPAC-1 and MIA PaCa-2 were all obtained from the American Type Culture Collection (ATCC; Manassas, VA, USA). All human pancreatic cancer cell lines were maintained in RPMI-1640 (Invitrogen; Thermo Fisher Scientific, Inc., Waltham, MA, USA) supplemented with $10 \%$ fetal bovine serum (HyClone; GE Healthcare, Logan, UT, USA) and $100 \mathrm{U} / \mathrm{ml}$ penicillin and $100 \mu \mathrm{g} / \mathrm{ml}$ streptomycin. Cells were maintained under a humidified atmosphere of $5 \% \mathrm{CO}_{2}$ at $37^{\circ} \mathrm{C}$.

Patients and tumor tissues. A total of 87 pancreatic cancer tissues and 8 adjacent normal tissues were obtained from 87 patients ( 51 males and 36 females) with a median age of 65 years old, undergoing surgery at the First Hospital of Jilin
University (Changchun, China) between January 2007 and December 2015. Adjacent normal tissues were taken from 8 of these patients ( 5 males and 3 females), with median age of 60 . Information regarding the response of patients to chemotherapy was obtained for only 63 patients with pancreatic cancer. Patients were diagnosed with pancreatic cancer based on clinicopathological evidence. Specimens were immediately snap-frozen and stored in liquid nitrogen tanks. Written informed consent from each patient enrolled in the study was obtained and ethical approval for the use of human tissues was obtained from the Institutional Research Ethics Committee at the First Hospital of Jilin University (ethics no. 2005-001). Clinicopathological information regarding the patients is presented in Tables I and II. Tumors were graded and classified according to the AJCC Cancer Staging Manual (22). The present study examined the expression of miR-374b-5p in the 87 pancreatic tissues and 8 adjacent normal tissues. Levels of miR-374b-5p expression in all pancreatic cancer tissues were normalized to that in the pancreatic cancer tissue with the lowest level of miR-374b-5p expression. Subsequently, the median miR-374b-5p expression in the pancreatic cancer tissues was used as the cutoff to distinguish between tissues exhibiting high and low expression of miR-374b-5p.

$R T-q P C R$. Total RNA from tissues or cells was extracted using an RNA Isolation kit (Qiagen, Inc., Valencia, CA, USA) following the manufacturer's protocol. mRNA and miRNA were reverse transcribed using the RevertAid First Strand cDNA Synthesis kit (Thermo Fisher Scientific, Inc.) according to the manufacturer's protocol. Reverse transcription was performed at $42^{\circ} \mathrm{C}$ for $60 \mathrm{~min}$ and $70^{\circ} \mathrm{C}$ for $10 \mathrm{~min}$.qPCR was performed using LightCycler $^{\circledR} 480$ SYBR-Green I Master (Roche Diagnostics, Basel, Switzerland). And was performed at $50^{\circ} \mathrm{C}$ for $3 \mathrm{~min}, 95^{\circ} \mathrm{C}$ for $10 \mathrm{~min}$, followed by 45 cycles of $95^{\circ} \mathrm{C}$ for $10 \mathrm{sec}, 60^{\circ} \mathrm{C}$ for $20 \mathrm{sec}$ and $70^{\circ} \mathrm{C}$ for $10 \mathrm{sec}$ and then increased from $66^{\circ} \mathrm{C}$ to $95^{\circ} \mathrm{C}$ to obtain the melting curve. Each sample was analyzed in triplicate. qPCR was performed according to a standard method, as previously described (23). The following primers were used in the qPCR reaction: BCL2, forward, 5'-TCCGCATCAGGAAGGCTAGA-3' and reverse, 5'-AGGACCAGGCCTCCAAGCT-3'; BIRC3, forward, 5'-TTTCCGTGGCTCTTATTCAAACT-3' and reverse, 5'-GCACAGTGGTAGGAACTTCTCAT-3'; XIAP, forward, 5'-AATAGTGCCACGCAGTCTACA-3' and reverse, 5'-CAG ATGGCCTGTCTAAGGCAA-3'; GAPDH, forward, 5'-ACA ACTTTGGTATCGTGGAAGG-3' and reverse, 5'-GCCATC ACGCCACAGTTTC-3'. Primers for U6 (patent no. MQP-0202; http://www.ribobio.com/sitecn/product_info.aspx?id=51) and miR-374b-5p (patent no. miRQ0004955-1-2, http://www.ribobio. com/sitecn/product_info.aspx?id=203689) were synthesized and purified by Guangzhou RiboBio (Guangzhou, China). U6 or GAPDH were used as endogenous controls for miRNA and mRNA, respectively. Relative fold expressions were calculated using the comparative threshold cycle $\left(2^{-\Delta \Delta \mathrm{Cq}}\right)$ method (24).

Plasmid, small interfering (si) RNA and transfection. The human miR-374b-5p expression plasmid was generated by cloning the genomic pre-miR-374b gene into the retroviral transfer plasmid pMSCV-puro (Takara Bio, Inc., Kusatsu, Japan) to generate the plasmid pMSCV-miR-374b-5p. pMSCV-miR-374b-5p was then cotransfected with the pIK packaging plasmid (cat no. 75483 ) into 
Table I. Clinicopathological information of the 87 patients with pancreatic cancer for microRNA-374b-5p expression analysis.

\begin{tabular}{|c|c|c|}
\hline & Cases (n) & Percentage $(\%)$ \\
\hline \multicolumn{3}{|l|}{ Sex } \\
\hline Male & 51 & 58.6 \\
\hline Female & 36 & 41.4 \\
\hline \multicolumn{3}{|l|}{ Age (years) } \\
\hline$\leq 60$ & 28 & 32.2 \\
\hline$>60$ & 59 & 67.8 \\
\hline \multicolumn{3}{|l|}{ Histopathology } \\
\hline Ductal adenocarcinoma & 70 & 80.5 \\
\hline Other & 17 & 19.5 \\
\hline \multicolumn{3}{|l|}{ Location } \\
\hline Head of pancreas & 71 & 81.6 \\
\hline Other & 16 & 18.4 \\
\hline \multicolumn{3}{|l|}{ Grade } \\
\hline G1 & 16 & 18.4 \\
\hline $\mathrm{G} 2$ & 47 & 54.0 \\
\hline G3 & 24 & 27.6 \\
\hline \multicolumn{3}{|l|}{ T classification } \\
\hline $\mathrm{T} 1$ & 8 & 9.2 \\
\hline $\mathrm{T} 2$ & 12 & 13.8 \\
\hline $\mathrm{T} 3$ & 60 & 69.0 \\
\hline $\mathrm{T} 4$ & 7 & 8.0 \\
\hline \multicolumn{3}{|l|}{$\mathrm{N}$ classification } \\
\hline No & 25 & 28.7 \\
\hline N1 & 62 & 71.3 \\
\hline \multicolumn{3}{|l|}{ M classification } \\
\hline M0 & 83 & 95.4 \\
\hline M1 & 4 & 4.6 \\
\hline \multicolumn{3}{|l|}{ Stage } \\
\hline Stage I & 13 & 14.9 \\
\hline Stage II & 64 & 73.6 \\
\hline Stage III & 6 & 6.9 \\
\hline Stage IV & 4 & 4.6 \\
\hline \multicolumn{3}{|l|}{ Chemotherapeutic response } \\
\hline Sensitivity & 29 & 33.3 \\
\hline Resistance & 34 & 39.1 \\
\hline Not available & 24 & 27.6 \\
\hline
\end{tabular}

Other histopathology includes: Adenocarcinoma not otherwise specified, mucinous carcinoma and neuroendocrine carcinoma. $\mathrm{T}$, tumor volume; $\mathrm{N}$, lymph node metastasis; $\mathrm{M}$, distant organ metastasis.

293FT cells (cat. no. CRL-1573) (both from ATCC) using the standard calcium phosphate transfection method, as previously described (25). A total of $36 \mathrm{~h}$ following co-transfection, supernatants were collected and incubated with cells to be infected for $24 \mathrm{~h}$ in the presence of polybrene $(2.5 \mu \mathrm{g} / \mathrm{ml})$. Following infection, puromycin $(1.5 \mu \mathrm{g} / \mathrm{ml})$ was used to select stably transduced cells over a 10-day period. The 3'-UTR regions of BCL2, BIRC3 and XIAP were amplified from genomic DNA using qPCR with 2x Phanta HS Master mix (cat. no. P512-01; Vazyme Biotech Co., Ltd, Nanjing, China) and using the thermocycling conditions described in the preceding paragraph. The primers used in the
Table II. Clinicopathological information of the 8 patients with pancreatic cancer that underwent microRNA-374b-5p expression analysis.

\begin{tabular}{lcc}
\hline & Cases (n) & Percentage (\%) \\
\hline Sex & 5 & \\
Male & 3 & 62.5 \\
Female & & 37.5 \\
Age (years) & 3 & \\
$\leq 60$ & 5 & 37.5 \\
$>60$ & & 62.5 \\
Histopathology & 6 & \\
Ductal adenocarcinoma & 2 & 75.0 \\
Other & & 25.0 \\
Location & 7 & \\
Head of pancreas & 1 & 87.5 \\
Other & & 12.5 \\
Grade & 1 & \\
G1 & 3 & 12.5 \\
G2 & 4 & 37.5 \\
G3 & & 50.0 \\
Stage & 2 & 62.5 \\
Stage I & 5 & 12.5 \\
Stage II & 1 & 0 \\
Stage III & 0 & \\
Stage IV & & \\
\hline
\end{tabular}

Other histopathology includes: Adenocarcinoma not otherwise specified ( 1 case) and neuroendocrine carcinoma (1 case).

PCR clone reactions are listed in Table III. They were then cloned into a pmirGLO luciferase reporter vector (Promega Corporation, Madison, WI, USA). The miArrest plasmids for anti-miR-374b-5p and negative controls were constructed and cloned into phU6 plasmids (Shanghai GeneChem Co., Ltd., Shanghai, China). The sequence of the anti-miR-374b-5p is CACTTAGCAGGTTGTAT TATAT. siRNAs for BCL2 (patent no. stB0003729A-1-5, http:// www.ribobio.com/sitecn/product_info.aspx?id=278148), BIRC3 (patent no. stB0001202A-1-5, http://www.ribobio.com/sitecn/ product_info.aspx?id=275621) and XIAP (patent no. stB0002398A-1-5, http://www.ribobio.com/sitecn/product_info. aspx?id=276817) knockdown and siRNA negative control (part of the BCL2, BIRC2 and XIAP siRNA kits) were obtained from Guangzhou Ribobio. Transfection of siRNAs and plasmids was performed using Lipofectamine 3000 (Thermo Fisher Scientific, Inc.) in BxPC-3 and SW1990 cells following the manufacturer's protocol. The concentration of each siRNA used in transfection was $50 \mathrm{nmol} / 1$, temperature was $37^{\circ} \mathrm{C}$ and the duration of transfection was $48 \mathrm{~h}$. The period of time between transfection and subsequent experimentation was $<7$ days.

Western blotting. Western blotting was performed following a previously described method (26). Briefly, cells were seeded in 100-mm tissue culture dishes. Following $24 \mathrm{~h}$, when cell confluence reached $60-70 \%$, cells were washed with prechilled PBS and proteins were extracted using sample buffer [62.5 mmol/1 Tris-HCl (pH 6.8), 2\% SDS, 10\% glycerol and 
$5 \%$ 2- $\beta$-mercaptoethanol]. The concentration of protein was determined using the BCA method. Equal amounts $(30 \mu \mathrm{g})$ of protein from the supernatant were loaded per lane and resolved using 9\% SDS-PAGE. Proteins were transferred onto a PVDF membrane (EMD Millipore, Billerica, MA, USA), blocked with $5 \%$ nonfat milk for $1 \mathrm{~h}$ at room temperature and probed with primary antibodies against BCL2 (cat. no. ab194583; Abcam, Cambridge, UK), BIRC3 (cat. no. 3130), XIAP (cat. no. 14334), cytochrome $c$ (cat. no. 11940, all dilution 1:1,000) (all from Cell Signaling Technology, Inc., Danvers, MA, USA) and mouse anti- $\alpha$-tubulin antibody (cat. no. ab7291, dilution, 1:5,000; Abcam) overnight at $4^{\circ} \mathrm{C}$. Membranes were washed three times (10 min/wash) in TBS-T buffer and incubated for $40 \mathrm{~min}$ at room temperature with horseradish peroxidaseconjugated anti-mouse (cat. no. 7076) or anti-rabbit (cat. no. 7074; Cell Signaling Technology,Inc.) secondary antibodies (both, dilution 1:5,000). Blots were then washed three times (10 min/wash) in TBS-T and developed using an enhanced chemiluminescence system (BeyoECL Plus, cat. no. P0018; Beyotime Institute of Biotechnology, Haimen, China). Protein loading was normalized by reprobing the blots with the mouse anti- $\alpha$-tubulin antibody.

Analysis of cell apoptosis. Flow cytometric analysis of apoptosis was performed using the fluorescein isothiocyanate (FITC) Annexin V Apoptosis Detection kit I (BD Biosciences, San Jose, CA, USA) and performed as previously described (27). Briefly, cells were dissociated with trypsin and resuspended at $1 \times 10^{6}$ cells $/ \mathrm{ml}$ in binding buffer with $50 \mu \mathrm{l} / \mathrm{ml}$ FITC Annexin V and $50 \mu \mathrm{l} / \mathrm{ml}$ propidium iodide (PI). Cells were subsequently incubated for $15 \mathrm{~min}$ at room temperature and analyzed using a Gallios flow cytometer (Beckman Coulter, Inc., Brea, CA, USA). The cell's inner mitochondrial membrane potential $(\Delta \psi \mathrm{m})$ was detected by flow cytometry using a MitoScreen JC-1 staining kit (BD Biosciences) following a previously described protocol (27). Briefly, cells were dissociated with trypsin, resuspended at $1 \times 10^{6}$ cells $/ \mathrm{ml}$ in assay buffer and then incubated at $37^{\circ} \mathrm{C}$ for $15 \mathrm{~min}$ with $10 \mu \mathrm{l} / \mathrm{ml} \mathrm{JC}-1$. Cells were washed twice with the assay buffer prior to analysis with the flow cytometer. Flow cytometric data were analyzed using FlowJo 7.6 software (FlowJo LLC, Ashland, OR, USA).

Quantification of pancreatic cell viability following treatment with gemcitabine. All pancreatic cancer cells, including BxPC-3, PANC-1, AsPC-1, SW1990, Capan-1, Capan-2, CFPAC-1 and MIA PaCa-2, were cultured in 96-well plates and treated with dimethyl sulfoxide (vehicle) or $10 \mu \mathrm{M}$ gemcitabine (cat. no. 1288463; Sigma-Aldrich; Merck KGaA, Darmstadt, Germany) for $36 \mathrm{~h}$ under a humidified atmosphere of $5 \% \mathrm{CO}_{2}$ at $37^{\circ} \mathrm{C}$. The number of live cells was quantified using the CellTiter-Glo ${ }^{\circledR}$ Luminescent Cell Viability Assay (cat. no. G7570; Promega Corporation). Surviving cells were calculated as the fraction of vehicle controls and the results were averaged between six wells per dose in three independent experiments.

Caspase- -9 and -3 activity assays. Caspase- -9 and -3 activity was analyzed by spectrophotometry using the caspase-9 (cat. no. KGA403) and caspase-3 (cat. no. KGA202) colorimetric assay kits, respectively (Nanjing Keygen Biotech, Co., Ltd.,
Nanjing, China), following the manufacturer's protocol. Briefly, $5 \times 10^{6}$ cells or $100 \mathrm{mg}$ fresh tumor tissues were washed with cold PBS, resuspended in lysis buffer and incubated on ice for $30 \mathrm{~min}$. A total of $50 \mu \mathrm{l}$ cell suspension, $50 \mu \mathrm{l}$ reaction buffer and $5 \mu 1$ caspase-3/-9 substrate was mixed and then incubated at $37^{\circ} \mathrm{C}$ for $4 \mathrm{~h}$. Absorbance was then measured at $405 \mathrm{~nm}$ and the results of BCA protein quantitative analysis were used as the reference to normalize expression in each experimental group.

High throughput data processing and visualization. Datasets regarding miRNA expression and the clinical profile of pancreatic cancer were downloaded from The Cancer Genome Atlas (TCGA: https://cancergenome.nih.gov/) and ArrayExpress (http://www.ebi.ac.uk/arrayexpress/). The $\log _{2}$ values of miRNAs in each sample were analyzed using Excel 2010 (Microsoft Corporation, Redmond, WA, USA) and GraphPad 5 (GraphPad, Inc., La Jolla, CA, USA). Differences in the miRNA expression of all pancreatic cancer tissues between the two groups were assessed using paired or unpaired t-tests. Datasets were downloaded from GSE24279 and GSE29352 (https://www.ncbi.nlm.nih.gov/geo/) to assess the expression of miRNAs in pancreatic cancer. The expression of miRNAs in each sample were analyzed as previously described (28). The expression of miR-374b-5p in pancreatic cancer datasets taken from TCGA and GSE was analyzed. Targetscan (http://www.targetscan.org/vert_71/) and miRanda (http://34.236.212.39/microrna/home.do) were used to predict the potential targets of miR-374b-5p and assessed using a previously described protocol $(29,30)$.

Tumor xenografts. A total of 20, 6-week-old female BALB/c-nu mice weighing 10-12 g were randomly divided into 4 groups (each, $\mathrm{n}=5$ ). Mice were kept at a temperature of $18-29^{\circ} \mathrm{C}$, humidity of $40-70 \%$ and under a 12 -h light-dark cycle. Mice also had ad libitum access to food and water mice. Cells $\left(2 \times 10^{6}\right)$ were inoculated subcutaneously into the inguinal folds of the nude mice. In 2 groups of mice, $2 \times 10^{6}$ control AsPC- 1 cells were inoculated subcutaneously in the left dorsal flank; in the other 2 groups, the mice were subcutaneously injected with the same number of miR-374b-5p overexpressing-AsPC-1 cells. At 7 days after the cell inoculation, one group of mice injected with the control cells and one group of mice injected with the anti-miR-149-5p cells received $50 \mu \mathrm{g} / \mathrm{g}$ gemcitabine (cat. no. 1288463, Sigma-Aldrich; Merck KGaA) via intraperitoneal injection twice a week for 4 weeks. Tumor volume was determined using an external caliper and calculated using the following equation: Length $\mathrm{x}$ (Weight $)^{2} / 2$. Tumor volume was assessed using the IVIS Spectrum In Vivo Imaging System (Perkin Elmer, Inc., Waltham, MA, USA) at 5-day intervals. On day 40, animals were euthanized via cervical dislocation. Tumors were excised, weighed and stored in liquid nitrogen tanks. Ethical approval for the animal study was obtained from the Institutional Research Ethics Committee from the First Hospital of Jilin University (ethics no. 2005-001).

Dual-luciferase reporter assay. Cells $\left(4 \times 10^{4}\right)$ were seeded in triplicate in 24-well plates and cultured for $24 \mathrm{~h}$. Subsequently, a dual-luciferase reporter assay was performed following a previously described protocol (31). Briefly, cells were plated 
Table III. Primer sequences used in the reactions for clone polymerase chain reaction.

\begin{tabular}{ll}
\hline Gene & \multicolumn{1}{c}{ Sequence (5'-3') } \\
\hline miR-374b-5p-clone-F & CGGATTAGGCACTGTGAATACAAAG \\
miR-374b-5p-clone-R & TCTGCCAGGTAGAGTGGGAAAC \\
BCL2-3'-UTR-F & GGGGGTTATCTGTACATCCTGGG \\
BCL2-3'-UTR-R & AACGATCACCTTTGCTCACAAATAG \\
BIRC3-3'-UTR-F & GTGGAAGAACAATTGCGGAGAC \\
BIRC3-3'-UTR-R & CCTGGCTTCATGTTCCCGGTATTAG \\
XIAP-3'-UTR-F & AGAACGTCCAGGGTTTACATTACAAG \\
XIAP-3'-UTR-R & GTGGCACCTGCCTGTAATTCC \\
\hline
\end{tabular}

F, forward; R, reverse; UTR, untranslated region; miR, microRNA; BCL2, B-cell lymphoma 2; BIRC3, Baculoviral IAP Repeat Containing 3; XIAP $\mathrm{X}$-linked inhibitor of apoptosis. The primer sequences for U6 were synthesized and purified by Guangzhou RiboBio (patent no. MQP-0202; http://www. ribobio.com/sitecn/product_info.aspx?id=51, Guangzhou, China).

in $60-\mathrm{mm}$ cell culture dishes and cultured for $24 \mathrm{~h}$ until they reached $60-80 \%$. Subsequently, $100 \mathrm{ng}$ BCL2-3'-UTR, BIRC3-3'-UTR or XIAP-3'-UTR luciferase plasmids, plus 5 ng pRL-TK Renilla plasmid (Promega Corporation) were transfected into cells using Lipofectamine 3000. Following 12-h incubation, the transfection medium was replaced; cells were harvested and washed with PBS and lysed using passive lysis buffer (Promega Corporation). Cell lysates were analyzed immediately using a Synergy ${ }^{\mathrm{TM}} 2$ microplate system (BioTek Instruments, Inc., Winooski, VT, USA). Luciferase and Renilla luciferase were measured using a dual-Luciferase Reporter assay system (Promega Corporation) following the manufacturer's protocol. The luciferase activity of each lysate was normalized to Renilla luciferase activity. The relative transcriptional activity was converted into fold induction above the vehicle control value.

miRNA immunoprecipitation (IP). Cells were co-transfected with pIRESneo-FLAG/human influenza hemagglutinin (HA)Ago2 plasmid (cat. no. 10822; Addgene, Inc., Cambridge, MA, USA), followed by HA-Ago2 IP using HA-antibody (dilution, 1:1,000; cat. no. H3663, Sigma-Aldrich; Merck KGaA), following a previously described protocol (32). Briefly, cells $\left(4 \times 10^{4}\right)$ were plated in $60-\mathrm{mm}$ cell culture dishes and cultured for $24 \mathrm{~h}$ until they reached $60-80 \%$ confluence. pIRESneoFLAG/HA-Ago2 plasmids were transfected into cells using Lipofectamine 3000. Following 48-h transfection, cells were washed and lysed in radioimmunoprecipitation buffer (Sigma-Aldrich; Merck KGaA) containing $10 \%$ proteinase inhibitor cocktail and $1 \mathrm{mM}$ phenylmethylsulfonyl fluoride. A fraction of the whole cell lysate was used for RNA isolation and the remaining lysate was subjected to IP using antibodies against HA (dilution, 1:1,000; cat. no. H3663; Sigma-Aldrich; Merck KGaA) or immunoglobulin G (dilution, 1:2,000; cat. no. ab109489; Abcam). RNA from whole cell lysates and RNA IP (RIP) fractions were extracted using TRIzol (Thermo Fisher Scientific, Inc.) following the manufacturer's protocol. Relative levels of mRNA were determined using RT-qPCR, following the aforementioned protocol. The relative mRNA enrichment in the RIP fractions was computed based on the ratio of relative mRNA levels in the RIP fractions and the relative mRNA levels in the whole cell lysates.

Statistical analysis. All values are presented as the mean \pm standard deviation. Significant differences were determined using GraphPad 5.0 software (GraphPad, Inc.). One-way analysis of variance was used to determine statistical differences between $\geq 2$ groups, followed by Tukey's post hoc test. Unpaired or paired t-tests were used to determine statistical differences between 2 groups. The $\chi^{2}$ test was used to analyze the association between miR-374b-5p expression and patient clinicopathological characteristics. Survival curves were plotted using the Kaplan Meier method and compared using the log-rank test using X-tile software version 3.6.1 (Yale University, New Haven, CT, USA). Pearson's correlation coefficient was used to analyze the correlation between miR-374b-5p expression levels and the apoptotic ratio following treatment with gemcitabine. $\mathrm{P}<0.05$ was considered to indicate a statistically significant difference. All experiments were repeated three times.

\section{Results}

miR-374b-5p expression is reduced in pancreatic cancer tissues. By analyzing several miRNA sequencing datasets of pancreatic cancer from TCGA and GSE using ArrayExpress, it was demonstrated that miR-374b-5p expression was significantly decreased in pancreatic cancer tissues compared with adjacent normal tissues (Fig. 1A-C). Subsequently, miR-374b-5p expression levels in the pancreatic cancer tissues taken from 8 patients recruited in the current study were measured and compared with miR-374-5p expression in the adjacent normal tissues. It was demonstrated that that miR-374b-5p expression was significantly decreased in 7 of the pancreatic cancer tissues compared with the respective adjacent normal tissue (Fig. 1D). Furthermore, miR-374-5p expression in the 87 pancreatic cancer tissues was significantly decreased compared with the normal tissues (Fig. 1E). The association between miR-374b-5p expression and the clinicopathological characteristics of patients with pancreatic cancer was then assessed and it was demonstrated that miR-374b-5p expression was inversely associated with node classification in patients with pancreatic cancer (Table IV). Kaplan-Meier survival analysis indicated that patients with pancreatic cancer that exhibited low expression of miR$374 b-5 p$ had significantly poorer overall and progression-free survival than those exhibiting high expression of miR374b-5p (Fig. 1F and G). This was also the case in patients from the TCGA dataset (Fig. $1 \mathrm{H}$ and I). These results indicate that miR-374b-5p expression is sigificantly reduced in pancreatic cancer tissues and that this is assiciated with increased mortality in patients with pancreatic cancer.

The low expression of miR-374b-5p is positively correlated with chemoresistance in pancreatic cancer. miRNA sequencing of the TCGA dataset containing patients with pancreatic cancer indicated that miR-374b-5p expression was significantly decreased in tissues from patients with drugresistant pancreatic cancer compared with those from patients 


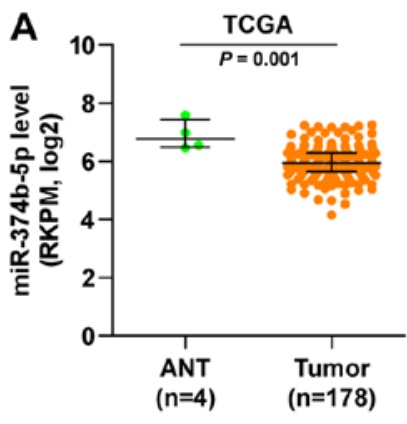

D

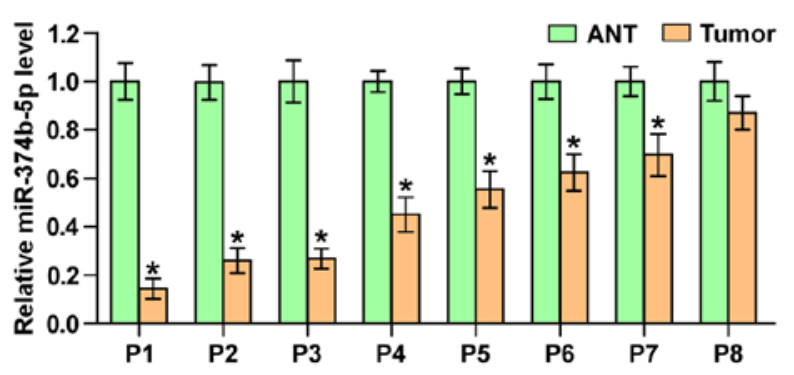

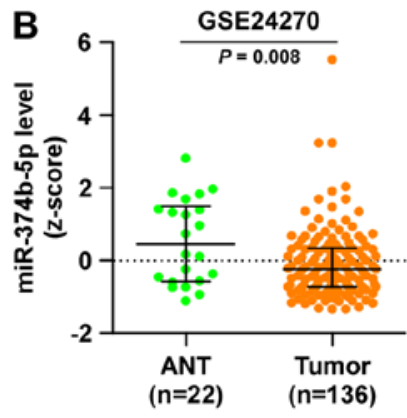

E

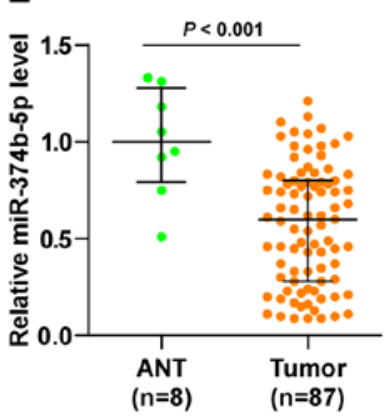

H

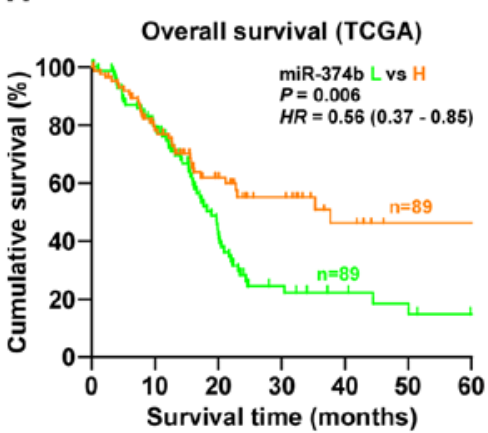

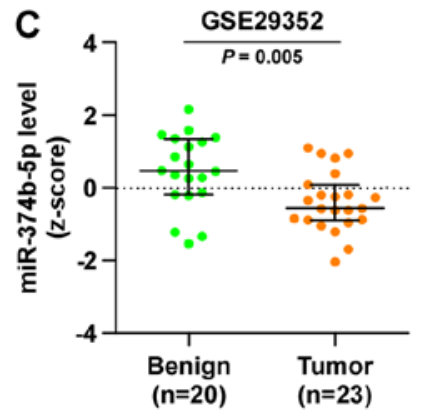

$\mathbf{F}$
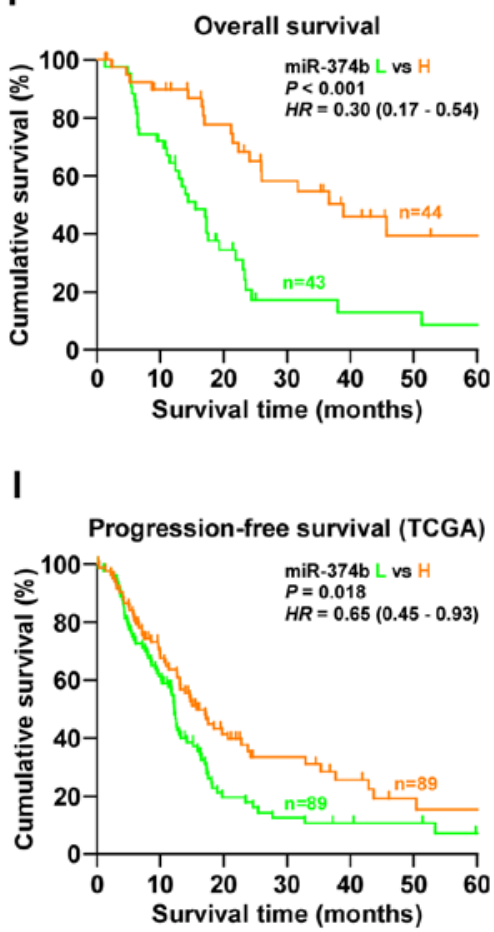

Figure 1. miR-374b-5p expression is decreased in pancreatic cancer tissues. (A) Analyzing the TCGA pancreatic cancer miRNA sequencing dataset indicated that miR-374b-5p expression was significantly decreased in pancreatic cancer tissues compared with ANTs. (B) Analysis of the GSE24270 pancreatic cancer miRNA sequencing dataset indicated that miR-374b-5p expression was decreased in pancreatic cancer tissues compared with ANTs. (C) Analysis of the GSE29352 pancreatic cancer miRNA sequencing dataset indicated that miR-374b-5p expression was decreased in pancreatic cancer tissues compared with ANTs. (D) miR-374b-5p expression was decreased in pancreatic cancer tissues compared with the 8 paired matched normal pancreatic tissues taken from patients in the current study. $\mathrm{P}<0.05$ vs. corresponding ANT (E) Analysis of patients included in the current study indicated that miR-374b-5p expression was decreased in pancreatic cancer tissues compared with ANTs. Kaplan-Meier analysis of (F) overall and (G) progression-free survival curves of patients with pancreatic cancer with low miR-374b-5p expression compared with those with high miR-374b-5p expression included in the current study. Kaplan-Meier analysis of $(\mathrm{H})$ overall and (I) progression-free survival curves of patients with low miR-374b-5p expression compared with those with high miR-374b-5p expression in the TCGA pancreatic cancer dataset. The optimal cutoff point was selected using the log-rank test using X-tile software. The results are presented as the mean \pm standard deviation of three independent experiments. ANT, adjacent normal tissue; miR, microRNA; TCGA, The Cancer Genome Atlas; L, low; H, high.

with drug-sensitive pancreatic cancer (Fig. 2A). This was also the case in patients recruited in the current study (Fig. 2B). The association between miR-374b-5p expression and the chemotherapeutic response of pancreatic cancer cells was evaluated by calculating the apoptotic ratio of pancreatic cancer cells treated with gemcitabine. As presented in Fig. 2C and D, pancreatic cancer cells with low expression of miR-374b-5p exhibited significantly increased resistance to gemcitabine compared with those that had high expression of miR-374b-5p. Furthermore, there was a positive correlation between miR-374b-5p expression and the apoptotic ratio of pancreatic cancer cells (Fig. 2E). Collectively, these results indicate that the low expression of miR-374b-5p is strongly associated with chemoresistance in pancreatic cancer.
Silencing miR-374b-5p promotes chemoresistance in pancreatic cancercells. The role of miR-374b-5pin the chemoresistance of pancreatic cancer was further investigated. The BxPC-3 and SW 1990 chemosensitive pancreatic cancer cells exhibited the highest expression of miR-374-5p (Fig. 2C); therefore, miR-374b-5p expression was knocked down by transfecting anti-miR-374b-5p into BxPC-3 and SW 1990 cells (Fig. 3A). An Annexin $\mathrm{V}$ apoptosis assay was performed and the results demonstrated that silencing miR-374b-5p expression significantly decreased the apoptotic ratio in BxPC-3 and SW 1990 cells following treatment with gemcitabine (Fig. 3B). A mitochondrial membrane potential assay was then performed and the results indicated that silencing miR-374b-5p significantly enhanced the mitochondrial potential of BxPC-3 and SW 
A

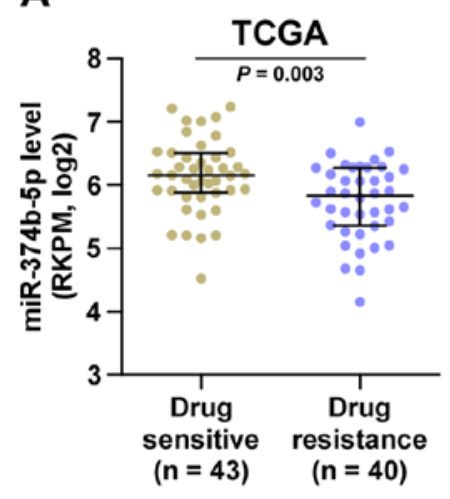

B

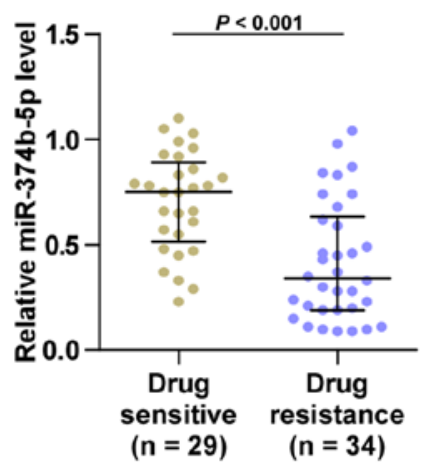

C $\square$ GEM resistance cells

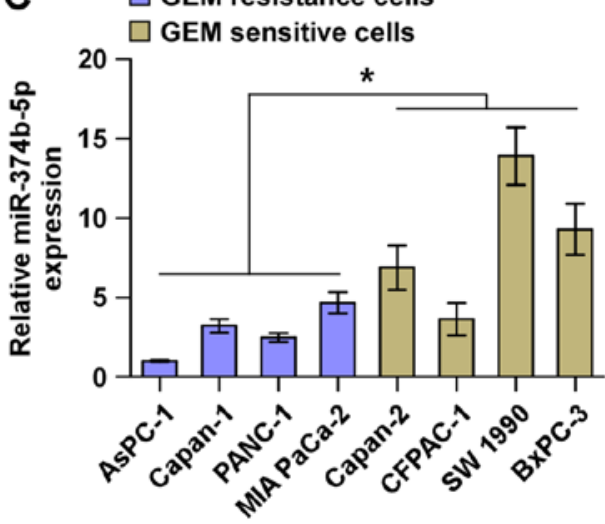

\section{D $\square$ GEM resistance cells \\ $\square$ GEM sensitive cells}

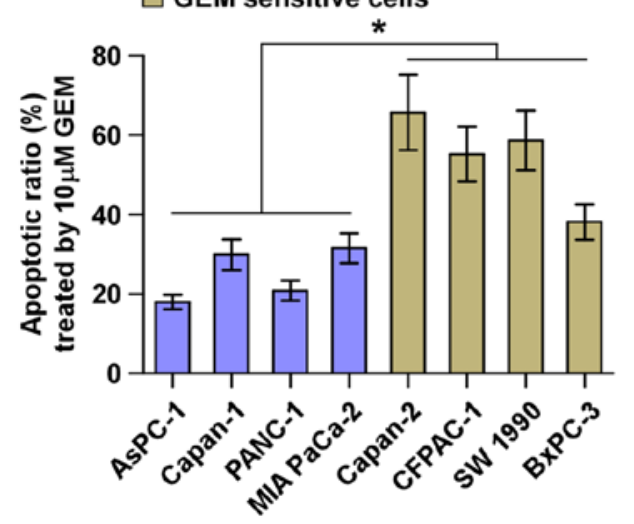

E

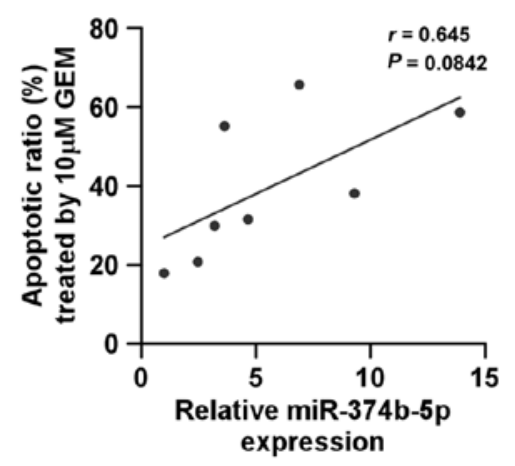

Figure 2. The decreased expression of miR-374b-5p is associated with chemoresistance in pancreatic cancer. (A) In the TCGA dataset, miR-374b-5p expression was reduced in chemoresistant pancreatic cancer tissues compared with chemosensitive pancreatic cancer tissues. (B) In tissues taken from patients included in the present study, miR-374b-5p expression was reduced in chemoresistant pancreatic cancer tissues compared with chemosensitive pancreatic cancer tissues. (C) Reverse transcription-quantitative polymerase chain reaction analysis of miR-374b-5p expression in pancreatic cancer cells. Transcript levels were normalized to U6 expression. (D) The apoptotic ratio of different pancreatic cancer cell lines following treatment with GEM. (E) The correlation between miR-374b-5p expression and the apoptotic ratio in pancreatic cancer cells following treatment with GEM. The results are presented as the mean \pm standard deviation of three independent experiments. "P<0.05. TCGA, The Cancer Genome Atlas; miR-374-5p, microRNA-374-5p; GEM, gemcitabine.

1990 cells following treatment with gemcitabine (Fig. 3C). Furthermore, silencing miR-374b-5p decreased the expression of cytochrome $c$ (Fig. 3D) and significantly decreased caspase-3 and -9 activity in BxPC-3 and SW 1990 cells following treatment with GEM (Fig. 3E). These results indicate that silencing miR-374b-5p induces the chemoresistance of pancreatic cancer cells to gemcitabine.

Ectopic expression of miR-374b-5p attenuates chemoresistance in pancreatic cancer cells. Subsequently, miR-374b-5p was overexpressed in AsPC-1 and PANC-1 cells via viral transduction (Fig. 4A), as these two cell lines expressed the lowest levels of miR-374b-5p (Fig. 2C). The upregulation of miR-374b-5p significantly increased the apoptotic ratio, the expression of cytochrome $c$ and caspase-3 and -9 activity, but significantly reduced the mitochondrial potential in AsPC-1 and PANC-3 cells following treatment with gemcitabine (Fig. 4B-E). These results demonstrate that the upregulation of miR-374b-5p abrogates the resistance of pancreatic cancer cells to gemcitabine.

Upregulation of miR-374b-5p ameliorates the resistance of pancreatic cancer cells to gemcitabine in vivo. To investigate the effect of miR-374b-5p on the chemoresistance of pancreatic cancer cells in vivo, mice were randomly divided into 4 groups ( $n=5 /$ group). In the first two groups of mice, $2 \times 10^{6}$ control AsPC-1 cells were inoculated subcutaneously into the left dorsal flank; in the other two groups, mice were subcutaneously injected with the same number of miR-374b-5p-overexpressing-AsPC-1 cells. Following 1 week, one control and one miR-374-5p-overexpressing group received an intraperitoneal injection of $50 \mu \mathrm{g} / \mathrm{g}$ gemcitabine twice per week over a 4-week period. Mice that received miR-374b-5p-overexpressing cells and gemcitabine treatment exhibited significantly smaller tumor volumes and weights (Fig. 5A-C) and significantly longer survival times compared with other three groups (Fig. 5D). Furthermore, caspase- 3 and -9 activity were significantly increased in the mice injected with miR-374b-5p-overexpressing cells and receiving gemcitabine treatment (Fig. 5E). These results indicate that the upregulation of miR-374b-5p restores the sensitivity of pancreatic cancer cells to gemcitabine in vivo.

miR-374b-5p targets multiple anti-apoptotic proteins in pancreatic cancer cells. By analyzing several public databases, including TargetScan and miRanda, it was determined 
A

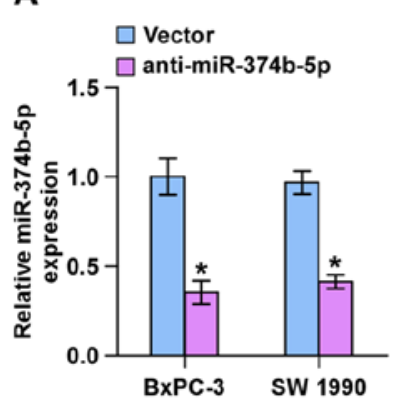

B

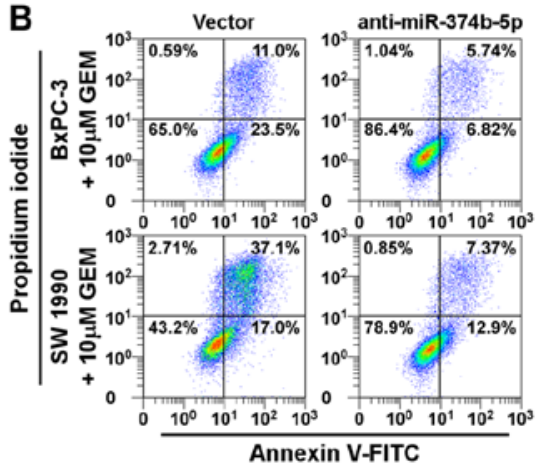

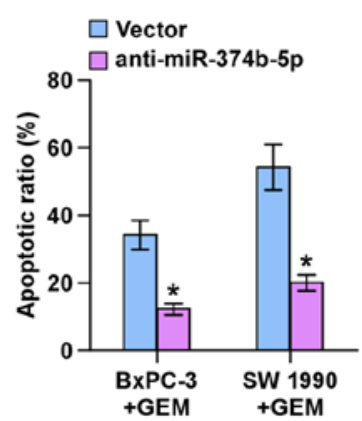

C

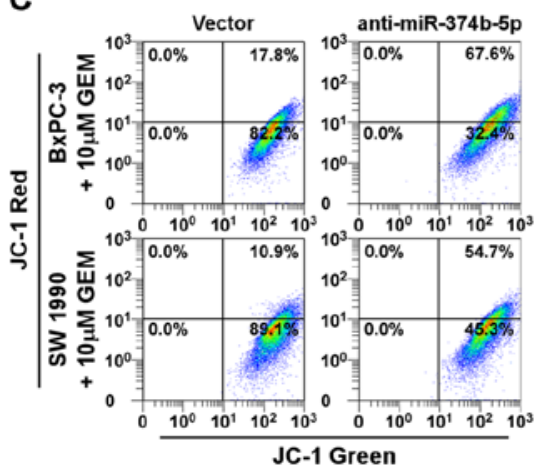

D

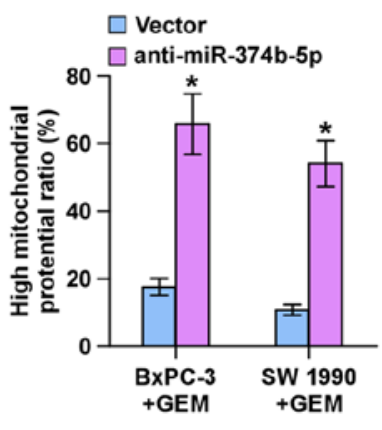

E

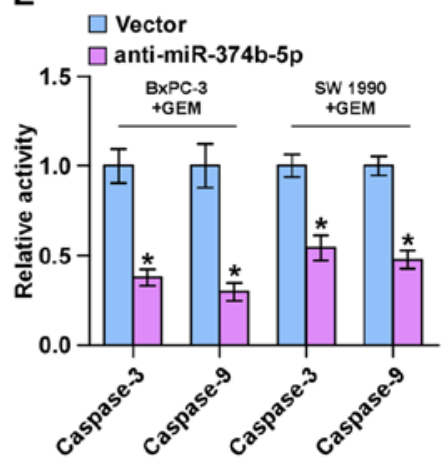

Figure 3. Downregulation of miR-374b-5p induces chemoresistance in BxPC-3 and SW1990 cells. (A) Reverse transcription-quantitative polymerase chain reaction analysis of miR-374b-5p expression. Transcript levels were normalized to U6 expression. (B) Annexin V-FITC/PI staining of cells treated with gemcitabine $(10 \mu \mathrm{M})$ for $36 \mathrm{~h}$. (C) JC-1 staining of the cells treated with GEM. (D) Western blotting analysis measuring CytoC expression. $\alpha$-tubulin served as the loading control. (E) Analysis of caspase-3 and -9 activity. All results are presented as the mean \pm standard deviation of three independent experiments. ${ }^{*} \mathrm{P}<0.05$ vs. vector. miR-374b-5p, microRNA-374b-5p; GEM, gemcitabine; CytoC, cytochrome $c$; FITC, fluorescin isothiocyanate; PI, propidium iodide.

that several anti-apoptotic proteins, including BCL2, BIRC3 and XIAP were potential targets of miR-374b-5p (Fig. 6A). The results of western blotting demonstrated that silencing miR-374b-5p increased the expression of BCL2, BIRC3 and XIAP in GEM-sensitive pancreatic cancer cell lines (Fig. 6B). Furthermore, the upregulation of miR-374b-5p significantly repressed the luciferase reporter activity of the 3'-UTRs of BCL2, BIRC3 and XIAP in pancreatic cancer cells (Fig. 6C), whereas silencing miR-374b-5p significantly elevated it (Fig. 6D). The results of the RNA IP assay identified a direct association between miR-374b-5p and BCL2, BIRC3 and XIAP transcripts (Fig. 6E and F). Collectively, these results demonstrate that BCL2, BIRC3 and XIAP are direct targets of miR-374b-5p in pancreatic cancer cells.

BCL2, BIRC3 and XIAP are crucial for the pro-chemoresistance effects of anti-miR-374b-5p on pancreatic cancer cells. It was then investigated whether BCL2, BIRC3 and XIAP mediate the functional effects of anti-miR-374b-5p on the chemoresistance of ovarian cancer cells. BCL2, BIRC3 and XIAP expression were silenced following transfection of siRNAs against BCL2, BIRC3 and XIAP into pancreatic cancer cells. The results of RT-qPCR demonstrated that silencing BCL2, BIRC3 and XIAP significantly reduced BCL2, BIRC3 and XIAP expression compared with the respective scramble controls (Fig. 6G). The silencing of BCL2, BIRC3 and XIAP expression significantly attenuated the stimulatory effects of anti-miR-374b-5p on the mitochondrial potential and caspase-3 and -9 activity, and reversed the inhibition of apoptosis induced by anti-miR-374b-5p in pancreatic cancer cells (Fig. 6H-K). Taken together, these results indicate that BCL2, BIRC3 and XIAP are crucial for the effects of anti-miR-374b-5p on the chemoresistance of pancreatic cancer cells.

\section{Discussion}

The present study indicates that miR-374b-5p serves a tumor suppressive role in chemotherapeutic resistant pancreatic cancer. miR-374b-5p expression was decreased in pancreatic cancer tissues, particularly in chemoresistant pancreatic cancer tissues, and the low expression of miR-374b-5p was strongly associated with chemotherapeutic resistance, as well as poor overall and progression-free survival in patients with pancreatic cancer. The upregulation of miR-374b-5p decreased, whereas miR-374b-5p silencing increased, the chemoresistance of pancreatic cancer cells to gemcitabine in vitro and in vivo. Furthermore, the results of the current study revealed that the upregulation of miR-374b-5p restored the chemotherapeutic sensitivity of pancreatic cancer cells to gemcitabine via the direct targeting of several anti-apoptotic proteins, including BCL2, BIRC3 and XIAP. Therefore, the results of the current study indicate that miR-374b-5p serves a tumor suppressive role in the development of chemotherapeutic resistance in pancreatic cancer.

BCL2 belongs to the Bcl-2 family and is an inhibitor of apoptosis. Previous studies have demonstrated that the upregulation of BCL2 contributes to intrinsic and acquired drug resistance in different types of human cancer (33-35). In 
A

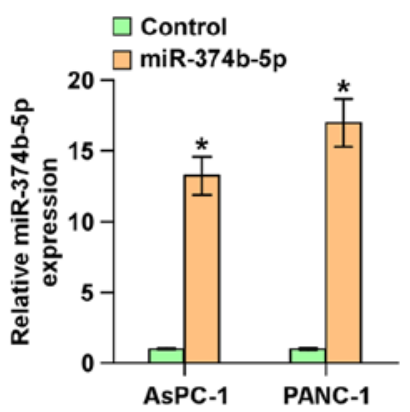

C

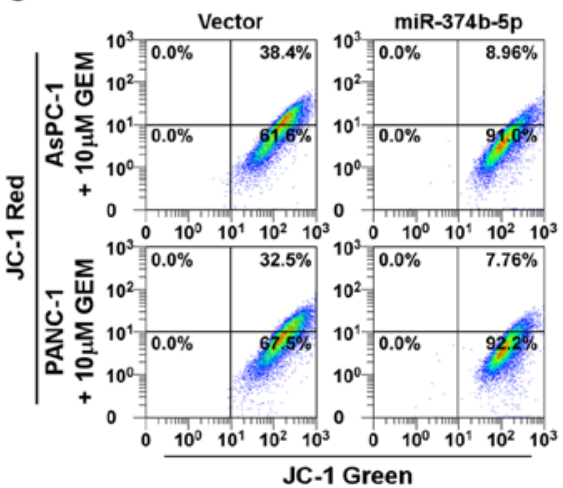

B

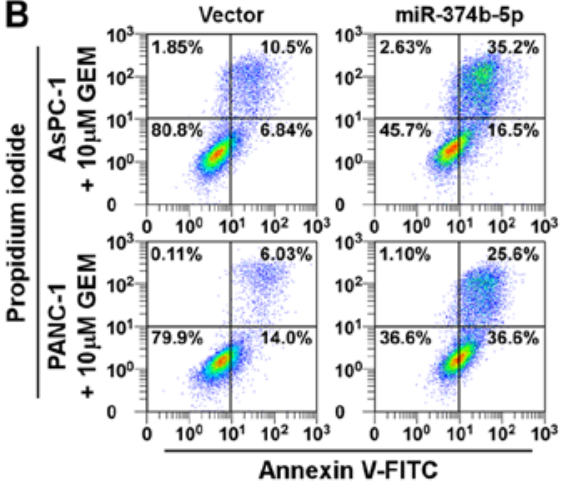

D

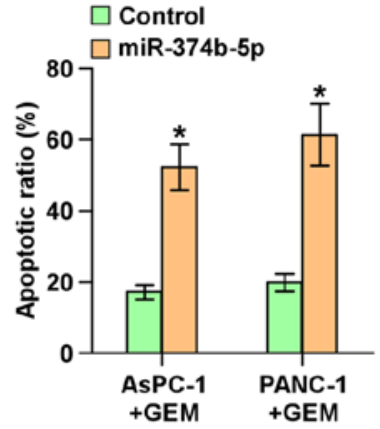

E
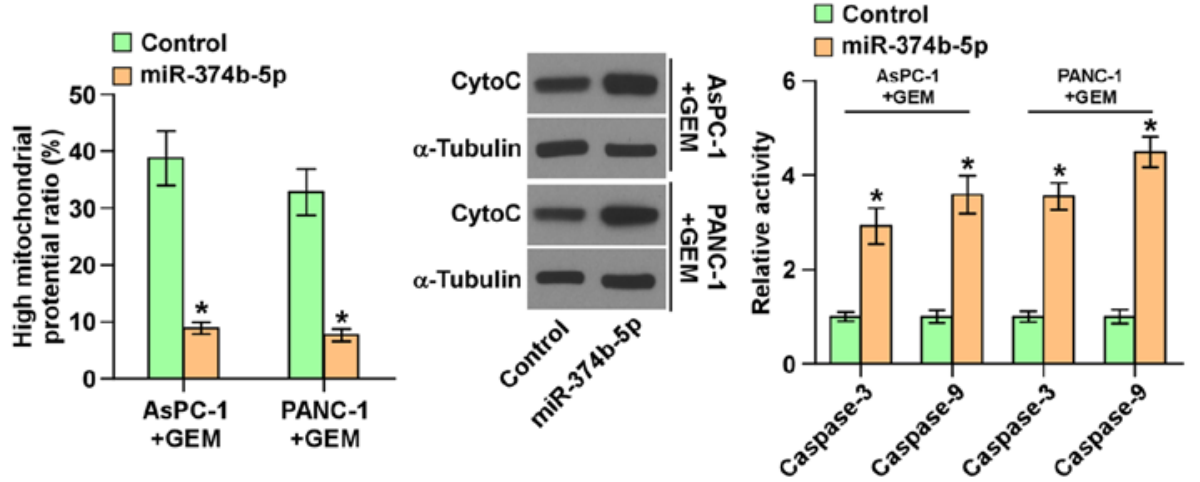

Figure 4. Upregulation of miR-374b-5p decreases the chemoresistance of AsPC-1 and PANC-1 cells. (A) Reverse transcription-quantitative polymerase chain reaction analysis of miR-374b-5p expression in the indicated pancreatic cancer cells. Transcript levels were normalized to U6 expression (B) Annexin V-FITC/ PI staining of the cells treated with gemcitabine $(10 \mu \mathrm{M})$ for $36 \mathrm{~h}$. (C) JC-1 staining of cells treated with GEM. (D) Western blotting measuring CytoC expression. $\alpha$-tubulin served as the loading control. (E) Analysis of caspase- 3 and -9 activity. Results are presented as the mean \pm standard deviation of three independent experiments. "P<0.05 vs. respective control. miR-374b-5p, microRNA-374b-5p; FITC, fluorescin isothiocyanate; PI, propidium iodide; CytoC, cytochrome $c$; GEM, gemcitabine.

A
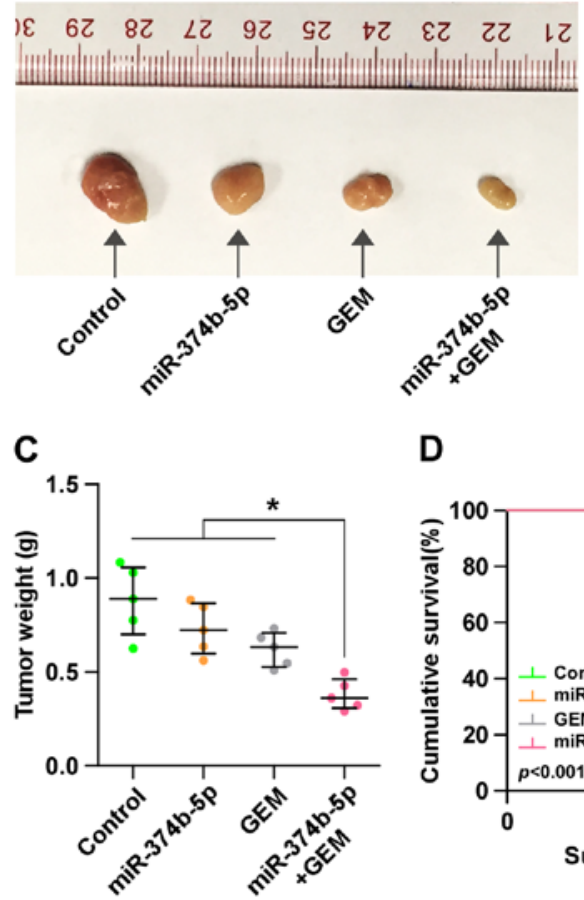

B

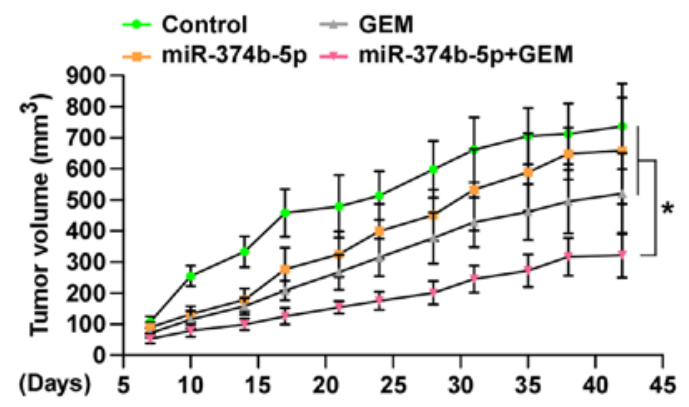

E

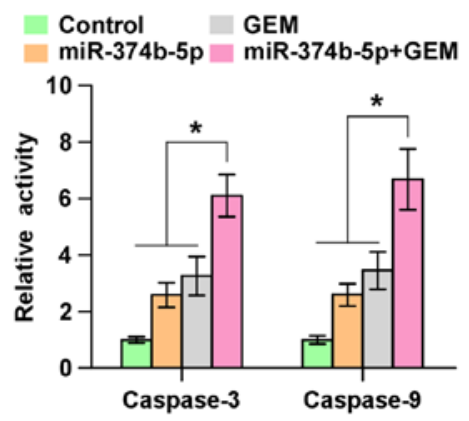

Figure 5. Upregulation of miR-374b-5p restores the sensitivity of pancreatic cancer cells to gemcitabine in vivo. (A) Representative images of the tumors in the xenograft model of nude mice are presented. (B) Following 10 days of inoculating the indicated AsPC-1 cells, mice were intraperitoneally injected with $50 \mu \mathrm{g} / \mathrm{g}$ GEM twice a week for 4 weeks. Tumor volumes were measured from the fifth day at intervals of 5 days. (C) Tumor weights of each group. (D) The overall survival of mice in the indicated group. (E) Caspase-3 and -9 activity in the indicated tumors. Data are presented are the mean \pm standard deviation. "P<0.05. miR-374b-5p, microRNA-374b-5p; GEM, gemcitabine. 
pancreatic cancer, the upregulation of BCL2 by the transcription factor cut like homeobox 1 significantly increased drug resistance (36). IAP proteins are another well-known family that act as endogenous inhibitors of apoptosis by directly binding to and inhibiting caspase proteins (37). The most well characterized IAP proteins include XIAP and BIRC3, which have been implicated in the chemoresistance of different types of cancer (38-40). Targeting Bcl-2 or IAP proteins markedly enhance the therapeutic effects of chemotherapeutic agents in various types of cancer $(41,42)$; however, it remains unknown how these anti-apoptotic proteins are simultaneously repressed in cancer. The results of the current study demonstrated that miR-374b-5p simultaneously targets BCL2, BIRC3 and XIAP, thus contributing to the chemoreistance of pancreatic cancer cells to gemcitabine. Therefore, the results of the current study identified a novel mechanism by which miR-374b-5p improves the chemotherapeutic response of pancreatic cancer to gemcitabine.

The dysregulation of miR-374b-5p has been implicated several disorders, including obesity, calcific aortic stenosis, ischemic stroke, IgA nephropathy and infertility (43-47). In cancer, the overexpression of miR-374b-5p has been identified in breast, head and neck, gastric and prostate cancer, as well as in melanoma (48-53). However, the downregulation of miR-374b-5p has also been identified in T-cell lymphoblastic lymphoma and colorectal cancer $(54,55)$. These results indicate that miR-374b-5p serves different roles in different types of tumor. Notably, a study by Schreiber et al (56) indicated that, following step-wise treatment with increasing concentrations of cisplatin over $>20$ passages, the downregulation of miR-374b-5p was directly involved in the development of the cisplatin-resistant phenotype. This suggests that the decreased expression of miR-374b-5p is associated with chemoresistance in pancreatic cancer. However, the clinical significance and underlying mechanism mediating the functional role of miR-374b-5p in pancreatic cancer are yet to be elucidated. The current study demonstrated that miR-374b-5p was downregulated in pancreatic cancer tissues and was associated with poor responses to chemotherapy, as well as poor overall and progression-free survival in patients with pancreatic cancer. Furthermore, the results of the current study indicate that the upregulation of miR-374b-5p reduces the chemotherapeutic resistance of pancreatic cancer cells to gemcitabine by inhibiting the expression of several anti-apoptotic proteins, including BCL2, BIRC3 and XIAP. This clarifies that miR-374b-5p serves a tumor suppressive role during the development of chemotherapeutic resistance in pancreatic cancer.

It has been suggested that miR-374b-5p may be used as a diagnostic marker in different types of cancer. Hanniford et al (50) reported that miR-374-b-5p has a diagnostic signature in patients with melanoma and brain metastasis compared with those without brain metastasis. Analysis of the TCGA dataset indicated that miR-374b-5p may be a prognostic marker of breast cancer (49). The results of the current study indicated that miR-374b-5p expression was dramatically reduced in pancreatic cancer tissues and the low expression of miR-374b-5p predicted the poor overall and progression-free survival of patients with pancreatic cancer. This indicates that miR-374b-5p may be used as a diagnostic marker in patients with pancreatic cancer. Importantly,
Table IV. The association between miR-374b-5p expression and the clinicopathological characteristics of the 87 patients with pancreatic cancer.

\begin{tabular}{|c|c|c|c|c|}
\hline \multirow[b]{2}{*}{ Parameters } & \multirow[b]{2}{*}{ No. of cases } & \multicolumn{2}{|c|}{$\begin{array}{c}\text { miR-374b-5p } \\
\text { expression }\end{array}$} & \multirow[b]{2}{*}{ P-values } \\
\hline & & Low & High & \\
\hline \multicolumn{5}{|l|}{ Sex } \\
\hline Male & 51 & 29 & 22 & 0.099 \\
\hline Female & 36 & 14 & 22 & \\
\hline \multicolumn{5}{|l|}{ Age (years) } \\
\hline$\leq 60$ & 28 & 16 & 12 & 0.321 \\
\hline$>60$ & 59 & 27 & 32 & \\
\hline \multicolumn{5}{|l|}{ Histopathology } \\
\hline Ductal adenocarcinoma & 70 & 35 & 35 & 0.828 \\
\hline Other & 17 & 8 & 9 & \\
\hline \multicolumn{5}{|l|}{ Location } \\
\hline Head of pancreas & 71 & 38 & 33 & 0.108 \\
\hline Other & 16 & 5 & 11 & \\
\hline \multicolumn{5}{|l|}{ Grade } \\
\hline G1-G2 & 63 & 31 & 32 & 0.947 \\
\hline G3 & 24 & 12 & 12 & \\
\hline \multicolumn{5}{|l|}{ T classification } \\
\hline $\mathrm{T} 1-2$ & 20 & 7 & 13 & 0.142 \\
\hline $\mathrm{T} 3-4$ & 67 & 36 & 31 & \\
\hline \multicolumn{5}{|l|}{$\mathrm{N}$ classification } \\
\hline No & 25 & 6 & 19 & $0.003^{\mathrm{a}}$ \\
\hline $\mathrm{N} 1-2$ & 62 & 37 & 25 & \\
\hline \multicolumn{5}{|l|}{ M classification } \\
\hline M0 & 83 & 39 & 44 & 0.055 \\
\hline M1 & 4 & 4 & 0 & \\
\hline \multicolumn{5}{|l|}{ Stage } \\
\hline I-II & 77 & 36 & 41 & 0.167 \\
\hline III-IV & 10 & 7 & 3 & \\
\hline \multicolumn{5}{|l|}{ Chemotherapeutic response } \\
\hline Sensitivity & 29 & 9 & 20 & $<0.001^{\mathrm{a}}$ \\
\hline Resistance & 34 & 25 & 9 & \\
\hline
\end{tabular}

${ }^{\mathrm{a}} \mathrm{P}<0.05$. Other histopathology includes: adenocarcinoma not otherwise specified, mucinous carcinoma, and neuroendocrine carcinoma. miR-374b-5p, microRNA-374b-5p.

Summerer et al (51) reported that high levels of miR-374b-5p in the plasma predicted the poor prognosis of patients with head and neck cancer, suggesting that miR-374b-5p may be used as a minimally invasive diagnostic marker in patients with cancer. However, further studies are required to determine whether miR-374b-5p levels in the serum or plasma may be used as a minimally invasive diagnostic or prognostic marker for patients with pancreatic cancer.

In conclusion, the results of the current study clarify that the upregulation of miR-374b-5p restores the chemotherapeutic resistance of pancreatic cancer cells to gemcitabine by directly repressing BCL2, BIRC 3 and XIAP expression. Comprehensive understanding of the underlying mechanism of miR-374b-5p in the chemoresistance of pancreatic cancer 
A

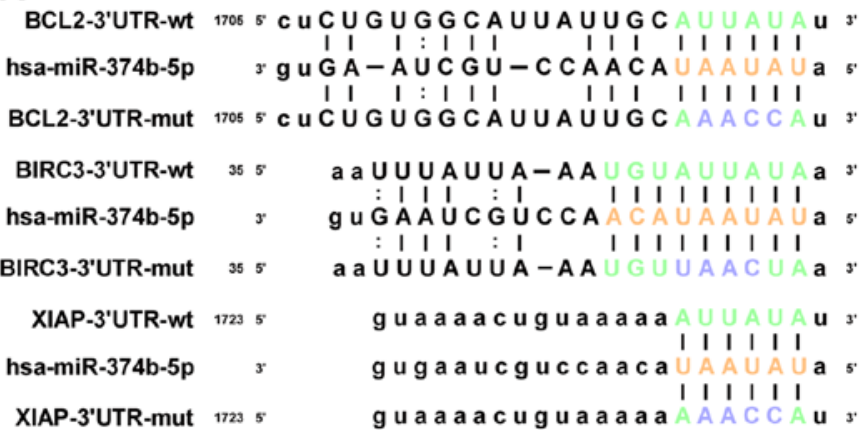

B

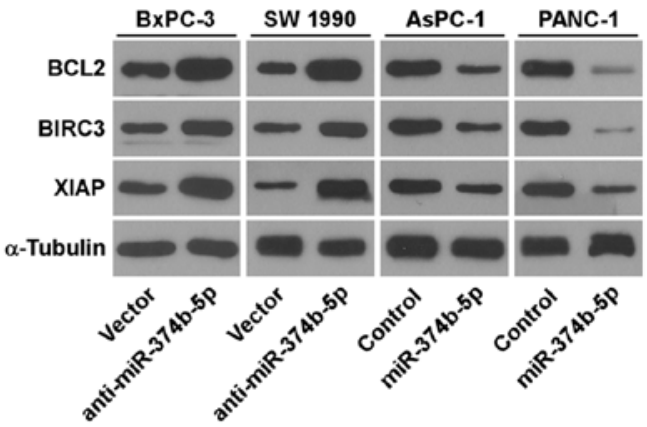

C

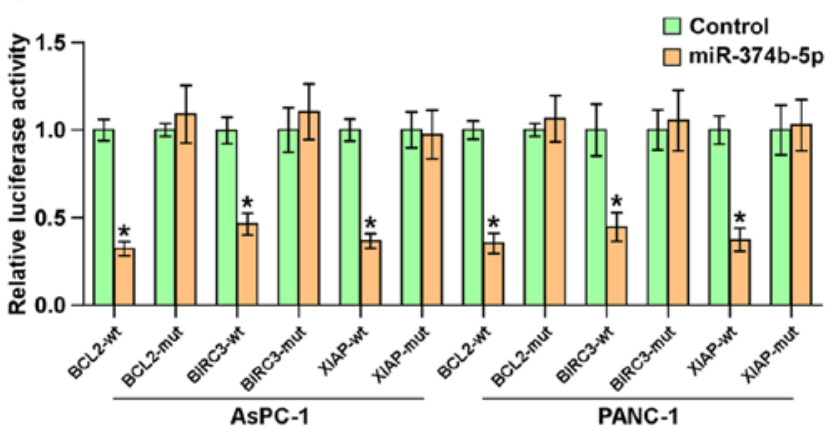

E

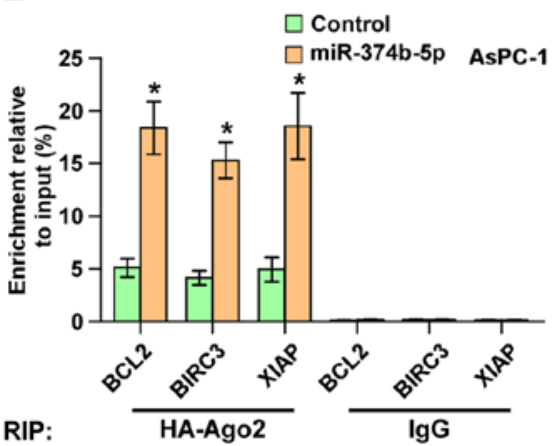

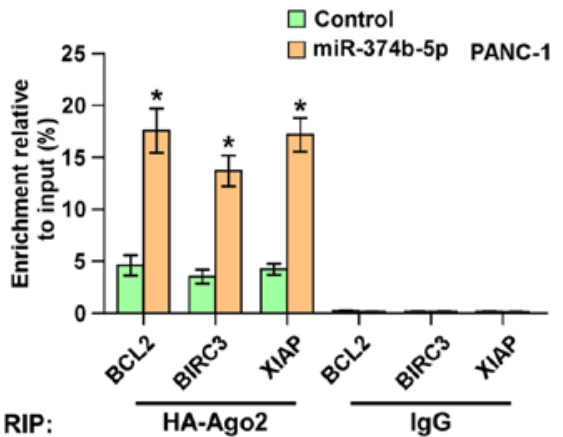

$\square$ Vector

$\square$ anti-miR-374b-5p

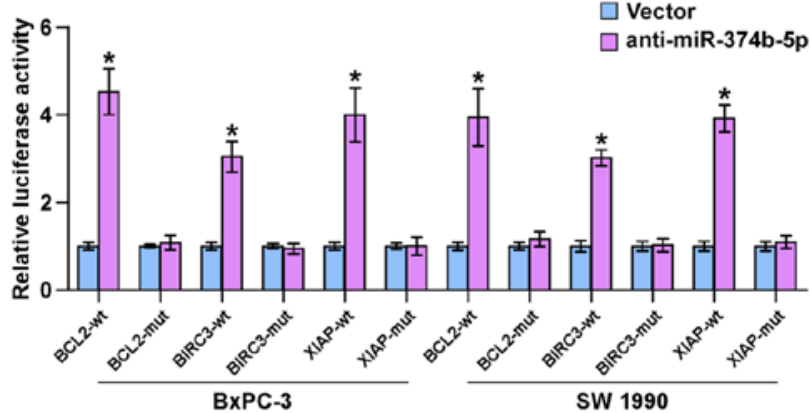

G

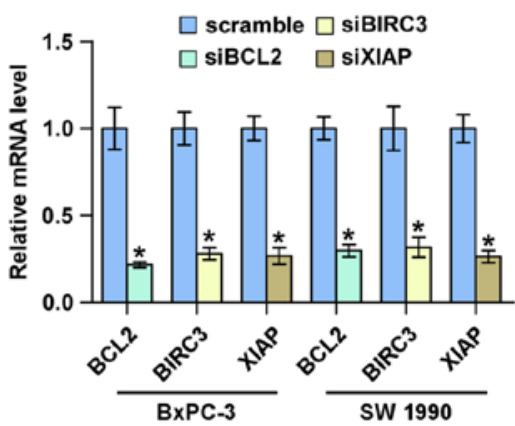

H

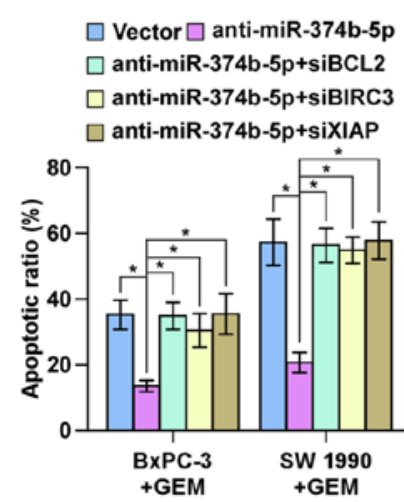

I

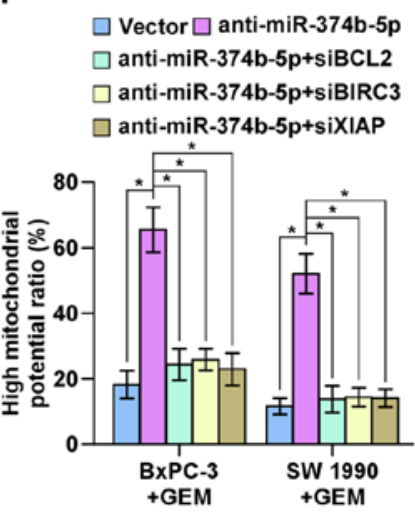

J

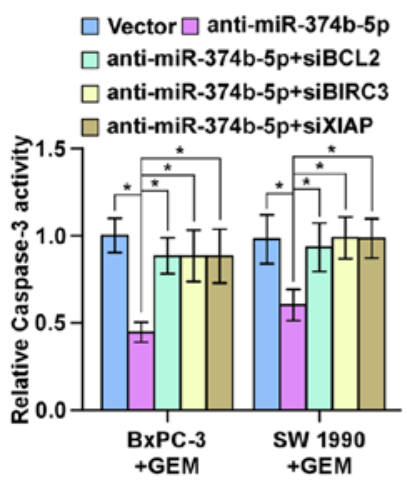

K

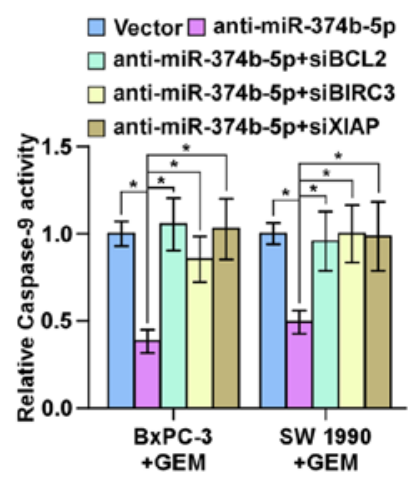

Figure 6. miR-374b-5p targets BCL2, BIRC3 and XIAP in pancreatic cancer cells. (A) Predicted miR-374b-5p target sequence in the 3'-UTRs of BCL2, BIRC3 and XIAP. (B) Western blotting measuring BCL2, BIRC3 and XIAP expression. $\alpha$-tubulin served as the loading control. (C and D) Luciferase assay of the cells transfected with the indicated reporter following transfection with (C) miR-374b-5p mimic or (D) anti-miR-374b-5p. ${ }^{*} \mathrm{P}<0.05$ vs. control or vector, respectively. (E and F) RNA immunoprecipitation assay indicating the association between miR-374b-5p and BCL2, BIRC3 and XIAP transcripts in the indicated cells. ${ }^{*} \mathrm{P}<0.05$ vs. vector $(\mathrm{G})$ Reverse transcription-quantitative polymerase chain reaction analysis of BCL2, BIRC 3 and XIAP expression in the indicated pancreatic cancer cells. Transcript levels were normalized to U6 expression. ${ }^{*} \mathrm{P}<0.05$ vs. scramble. $(\mathrm{H})$ The protective effect of anti-miR-374b-5p on the apoptotic rate of pancreatic cancer cells was attenuated by the individual silencing of BCL2, BIRC3 and XIAP. (I) The stimulatory effect of anti-miR-374b-5p on the mitochondrial potential of pancreatic cancer cells was attenuated by the individual silencing of BCL2, BIRC3 and XIAP. (J and K) The stimulatory effects of anti-miR-374b-5p on caspase-3 and -9 activity of pancreatic cancer cells was attenuated by the silencing of BCL2, BIRC3 and XIAP. Data are presented as the mean \pm standard deviation of three independent experiments. "P<0.05. miR-374b-5p, microRNA-374b-5p; BCL2, B-cell lymphoma 2; BRIC3, Baculoviral IAP Repeat Containing 3; XIAP, X-linked inhibitor of apoptosis; UTR, untranslated region; mut, mutant; wt, wild-type; si, small interfering; GEM, gemcitabine. 
may provide insights into the development of chemoresistance in pancreatic cancer, which may facilitate the development of novel therapeutic methods to treat patients with pancreatic cancer.

\section{Acknowledgements}

Not applicable.

\section{Funding}

The present study was supported by grants from the Finance Department Foundation of Jilin Province (120170627191002).

\section{Availability of data and materials}

The datasets generated and analyzed in the current study are available at TCGA (https://cancergenome.nih.gov/) and ArrayExpress (http://www.ebi.ac.uk/arrayexpress/)

\section{Authors' Contributions}

PZ conceived the experiments and drafted the manuscript. DS and XW conducted the experiments and helped to analyze the data. GS performed data analysis. SC and MY performed data analysis and revised the manuscript. All authors contributed to revise the manuscript and approved the final version for publication.

\section{Ethics approval and consent to participate}

Written informed consent from each patient enrolled in the study was obtained and ethical approval for the use of human tissues and for the animal study was obtained from the Institutional Research Ethics Committee at The First Hospital of Jilin University (ethics no. 005-001).

\section{Consent for publication}

Not applicable.

\section{Competing interests}

The authors declare that they have no conflicts of interest.

\section{References}

1. Jemal A, Siegel R, Ward E, Murray T, Xu J, Smigal C and Thun MJ: Cancer statistics, 2006. CA Cancer J Clin 56: 106-130, 2006.

2. Bond-Smith G, Banga N, Hammond TM and Imber CJ: Pancreatic adenocarcinoma. BMJ 344: e2476, 2012.

3. Merl MY, Abdelghany O, Li J and Saif MW: First-line treatment of metastatic pancreatic adenocarcinoma: Can we do better? Highlights from the '2010 ASCO Annual Meeting'. Chicago, IL, USA. June 4-8, 2010. JOP 11: 317-320, 2010.

4. Kindler HL: Front-line therapy of advanced pancreatic cancer. Semin Oncol 32 (Suppl 9): S33-S36, 2005.

5. Gonzalez-Angulo AM, Morales-Vasquez F and Hortobagyi GN: Overview of resistance to systemic therapy in patients with breast cancer. Adv Exp Med Biol 608: 1-22, 2007.

6. Gottesman MM and Pastan IH: The role of multidrug resistance efflux pumps in cancer: Revisiting a JNCI publication exploring expression of the MDR1 (P-glycoprotein) gene. J Natl Cancer Inst 107: 107, 2015.
7. Radin D, Lippa A, Patel P and Leonardi D: Lifeguard inhibition of Fas-mediated apoptosis: A possible mechanism for explaining the cisplatin resistance of triple-negative breast cancer cells. Biomed Pharmacother 77: 161-166, 2016.

8. Ojini I and Gammie A: Rapid identification of chemoresistance mechanisms using yeast DNA mismatch repair mutants. G3 (Bethesda) 5: 1925-1935, 2015.

9. Aldinucci D, Celegato M and Casagrande N: Microenvironmental interactions in classical Hodgkin lymphoma and their role in promoting tumor growth, immune escape and drug resistance. Cancer Lett 380: 243-252, 2016.

10. Mastri M, Rosario S, Tracz A, Frink RE, Brekken RA and Ebos JM: The challenges of modeling drug resistance to antiangiogenic therapy. Curr Drug Targets 17: 1747-1754, 2016.

11. Gottesman MM: Mechanisms of cancer drug resistance. Annu Rev Med 53: 615-627, 2002.

12. Bartel DP: MicroRNAs: Target recognition and regulatory functions. Cell 136: 215-233, 2009.

13. Ren D, Wang M, Guo W, Huang S, Wang Z, Zhao X, Du H, Song L and Peng X: Double-negative feedback loop between ZEB2 and miR-145 regulates epithelial-mesenchymal transition and stem cell properties in prostate cancer cells. Cell Tissue Res 358: 763-778, 2014.

14. Ren D, Wang M, Guo W, Zhao X, Tu X, Huang S, Zou X and Peng X: Wild-type p53 suppresses the epithelial-mesenchymal transition and stemness in PC-3 prostate cancer cells by modulating miR 145. Int J Oncol 42: 1473-1481, 2013.

15. Li X, Jin Y, Mu Z, Chen W and Jiang S: MicroRNA 146a 5p enhances cisplatin induced apoptosis in ovarian cancer cells by targeting multiple anti apoptotic genes. Int J Oncol 51: 327-335, 2017.

16. Feng C, Sun P, Hu J, Feng H, Li M, Liu G, Pan Y, Feng Y, Xu Y, Feng K, et al: miRNA-556-3p promotes human bladder cancer proliferation, migration and invasion by negatively regulating DAB2IP expression. Int J Oncol 50: 2101-2112, 2017.

17. Zhang X, Liu J, Zang D, Wu S, Liu A, Zhu J, Wu G, Li J and Jiang L: Upregulation of miR-572 transcriptionally suppresses SOCS1 and p21 and contributes to human ovarian cancer progression. Oncotarget 6: 15180-15193, 2015.

18. Ren D, Yang Q, Dai Y, Guo W, Du H, Song L and Peng X: Oncogenic miR-210-3p promotes prostate cancer cell EMT and bone metastasis via NF- $\kappa \mathrm{B}$ signaling pathway. Mol Cancer 16: $117,2017$.

19. Guo W, Ren D, Chen X, Tu X, Huang S, Wang M, Song L, Zou X and Peng X: HEF1 promotes epithelial mesenchymal transition and bone invasion in prostate cancer under the regulation of microRNA-145. J Cell Biochem 114: 1606-1615, 2013.

20. Chaudhary AK, Mondal G, Kumar V, Kattel K and Mahato RI: Chemosensitization and inhibition of pancreatic cancer stem cell proliferation by overexpression of microRNA-205. Cancer Lett 402: 1-8, 2017.

21. Chen M, Wang M, Xu S, Guo X and Jiang J: Upregulation of miR-181c contributes to chemoresistance in pancreatic cancer by inactivating the Hippo signaling pathway. Oncotarget 6: 44466-44479, 2015.

22. Amin MB, Greene FL, Edge SB, Compton CC, Gershenwald JE, Brookland RK, Meyer L, Gress DM, Byrd DR and Winchester DP: The Eighth Edition AJCC Cancer Staging Manual: Continuing to build a bridge from a population-based to a more 'personalized' approach to cancer staging. CA Cancer J Clin 67: 93-99, 2017.

23. Wang M, Ren D, Guo W, Huang S, Wang Z, Li Q, Du H, Song L and Peng X: N-cadherin promotes epithelial-mesenchymal transition and cancer stem cell-like traits via ErbB signaling in prostate cancer cells. Int J Oncol 48: 595-606, 2016.

24. Livak KJ and Schmittgen TD: Analysis of relative gene expression data using real-time quantitative PCR and the 2(-Delta Delta C(T)) method. Methods 25: 402-408, 2001.

25. Hahn WC, Dessain SK, Brooks MW, King JE, Elenbaas B, Sabatini DM, DeCaprio JA and Weinberg RA: Enumeration of the simian virus 40 early region elements necessary for human cell transformation. Mol Cell Biol 22: 2111-2123, 2002.

26. Zhang X, Ren D, Guo L, Wang L, Wu S, Lin C, Ye L, Zhu J, Li J, Song L, et al: Thymosin beta 10 is a key regulator of tumorigenesis and metastasis and a novel serum marker in breast cancer. Breast Cancer Res 19: 15, 2017.

27. Ren D, Lin B, Zhang X, Peng Y, Ye Z, Ma Y, Liang Y, Cao L, Li X, Li R, et al: Maintenance of cancer stemness by miR-196b-5p contributes to chemoresistance of colorectal cancer cells via activating STAT3 signaling pathway. Oncotarget 8: 49807-49823, 2017. 
28. Cheadle C, Vawter MP, Freed WJ and Becker KG: Analysis of microarray data using $\mathrm{Z}$ score transformation. J Mol Diagn 5: 73-81, 2003.

29. Betel D, Wilson M, Gabow A, Marks DS and Sander C: The microRNA.org resource: Targets and expression. Nucleic Acids Res 36: D149-D153, 2008.

30. Agarwal V, Bell GW, Nam JW and Bartel DP: Predicting effective microRNA target sites in mammalian mRNAs. Elife: Aug 12, 2015 (Epub ahead of print). doi: 10.7554/eLife.05005.

31. Zhang X, Zhang L, Lin B, Chai X, Li R, Liao Y, Deng X, Liu Q, Yang W, Cai Y, et al: Phospholipid phosphatase 4 promotes proliferation and tumorigenesis, and activates $\mathrm{Ca}^{2+}$-permeable cationic channel in lung carcinoma cells. Mol Cancer 16: 147, 2017.

32. Li X, Liu F, Lin B, Luo H, Liu M, Wu J, LiC, Li R, Zhang X, Zhou K et al: $\mathrm{miR} 150$ inhibits proliferation and tumorigenicity via retarding G1/S phase transition in nasopharyngeal carcinoma. Int J Oncol: Mar 10, 2017 (Epub ahead of print). doi: 10.3892/ijo.2017.3909.

33. Johnstone RW, Ruefli AA and Lowe SW: Apoptosis: A link between cancer genetics and chemotherapy. Cell 108: 153-164, 2002.

34. Reed JC: Bcl-2 and the regulation of programmed cell death. J Cell Biol 124: 1-6, 1994.

35. Reed JC: Dysregulation of apoptosis in cancer. J Clin Oncol 17: 2941-2953, 1999.

36. Ripka S, Neesse A, Riedel J, Bug E, Aigner A, Poulsom R, Fulda S, Neoptolemos J, Greenhalf W, Barth P, et al: CUX1: Target of Akt signalling and mediator of resistance to apoptosis in pancreatic cancer. Gut 59: 1101-1110, 2010.

37. Deveraux QL, Takahashi R, Salvesen GS and Reed JC: X-linked IAP is a direct inhibitor of cell-death proteases. Nature 388: 300-304, 1997.

38. Mendoza-Rodríguez M, Arévalo Romero H,Fuentes-Pananá EM, Ayala-Sumuano JT and Meza I: IL-1 $\beta$ induces up-regulation of BIRC3, a gene involved in chemoresistance to doxorubicin in breast cancer cells. Cancer Lett 390: 39-44, 2017.

39. Cillessen SA, Reed JC, Welsh K, Pinilla C, Houghten R, Hooijberg E, Deurhof J, Castricum KC, Kortman P, Hess CJ, et al: Small-molecule XIAP antagonist restores caspase-9 mediated apoptosis in XIAP-positive diffuse large B-cell lymphoma cells. Blood 111: 369-375, 2008.

40. Fakler M,Loeder S, Vogler M,Schneider K,Jeremias I,Debatin KM and Fulda S: Small molecule XIAP inhibitors cooperate with TRAIL to induce apoptosis in childhood acute leukemia cells and overcome Bcl-2-mediated resistance. Blood 113: 1710-1722, 2009.

41. Kashkar H, Deggerich A, Seeger JM, Yazdanpanah B Wiegmann K, Haubert D, Pongratz C and Krönke M: NF-kappaBindependent down-regulation of XIAP by bortezomib sensitizes HL B cells against cytotoxic drugs. Blood 109: 3982-3988, 2007.

42. Kater AP, Dicker F, Mangiola M, Welsh K, Houghten R, Ostresh J, Nefzi A, Reed JC, Pinilla C and Kipps TJ: Inhibitors of XIAP sensitize CD40-activated chronic lymphocytic leukemia cells to CD95-mediated apoptosis. Blood 106: 1742-1748, 2005.

43. Jones A, Danielson KM, Benton MC, Ziegler O, Shah R, Stubbs RS, Das S and Macartney-Coxson D: miRNA signatures of insulin resistance in obesity. Obesity (Silver Spring) 25: 1734$1744,2017$.
44. Xu HX, Wang Y, Zheng DD, Wang T, Pan M, Shi JH, Zhu JH and $\mathrm{Li}$ XF: Differential expression of microRNAs in calcific aortic stenosis. Clin Lab 63: 1163-1170, 2017.

45. Tan JR, Tan KS, Yong FL, Armugam A, Wang CW, Jeyaseelan K and Wong PT: MicroRNAs regulating cluster of differentiation 46 (CD46) in cardioembolic and non-cardioembolic stroke. PLoS One 12: e0172131, 2017.

46. Hu S, Bao H, Xu X, Zhou X, Qin W, Zeng C and Liu Z: Increased miR-374b promotes cell proliferation and the production of aberrant glycosylated IgA1 in B cells of IgA nephropathy. FEBS Lett 589: 4019-4025, 2015.

47. Wang C, Yang C, Chen X, Yao B, Yang C, Zhu C, Li L, Wang J, Li X, Shao Y, et al: Altered profile of seminal plasma microRNAs in the molecular diagnosis of male infertility. Clin Chem 57: 1722-1731, 2011.

48. Zhang K, Wang YW, Wang YY, Song Y, Zhu J, Si PC and Ma R: Identification of microRNA biomarkers in the blood of breast cancer patients based on microRNA profiling. Gene 619: 10-20, 2017.

49. Chang JT, Wang F, Chapin W and Huang RS: Identification of microRNAs as breast cancer prognosis markers through the cancer genome atlas. PLoS One 11: e0168284, 2016.

50. Hanniford D, Zhong J, Koetz L, Gaziel-Sovran A, Lackaye DJ, Shang S, Pavlick A, Shapiro R, Berman R, Darvishian F, et al: A miRNA-based signature detected in primary melanoma tissue predicts development of brain metastasis. Clin Cancer Res 21: 4903-4912, 2015.

51. Summerer I, Unger K, Braselmann H, Schuettrumpf L, Maihoefer C, Baumeister P, Kirchner T, Niyazi M, Sage E, Specht HM, et al: Circulating microRNAs as prognostic therapy biomarkers in head and neck cancer patients. Br J Cancer 113: 76-82, 2015.

52. Xie J, Tan ZH, Tang X, Mo MS, Liu YP, Gan RL, Li Y, Zhang L and Li GQ: MiR-374b-5p suppresses RECK expression and promotes gastric cancer cell invasion and metastasis. World J Gastroenterol 20: 17439-17447, 2014

53. He HC, Han ZD, Dai QS, Ling XH, Fu X, Lin ZY, Deng YH, Qin GQ, Cai C, Chen JH, et al: Global analysis of the differentially expressed miRNAs of prostate cancer in Chinese patients. BMC Genomics 14: 757, 2013.

54. Qian D, Chen K, Deng H, Rao H, Huang H, Liao Y, Sun X, Lu S, Yuan Z, Xie D, et al: MicroRNA-374b suppresses proliferation and promotes apoptosis in T-cell lymphoblastic lymphoma by repressing AKT1 and Wnt-16. Clin Cancer Res 21: 4881-4891, 2015.

55. Wu X, Li S, Xu X, Wu S, Chen R, Jiang Q, Li Y and Xu Y: The potential value of miR-1 and miR-374b as biomarkers for colorectal cancer. Int J Clin Exp Pathol 8: 2840-2851, 2015.

56. Schreiber R, Mezencev R, Matyunina LV and McDonald JF: Evidence for the role of microRNA $374 \mathrm{~b}$ in acquired cisplatin resistance in pancreatic cancer cells. Cancer Gene Ther 23 241-245, 2016.

This work is licensed under a Creative Commons Attribution-NonCommercial-NoDerivatives 4.0 International (CC BY-NC-ND 4.0) License. 